\title{
Intestinal flora of FAP patients containing APC-like sequences
}

\author{
K. HAINOVA ${ }^{1}$, Z. ADAMCIKOVA ${ }^{1}$, S. CIERNIKOVA ${ }^{1}$, V. STEVURKOVA ${ }^{1}$, S. TYCIAKOVA ${ }^{2}$, V. ZAJAC ${ }^{1, *}$
}

${ }^{1}$ Department of Cancer Genetics, Cancer Research Institute, Slovak Academy of Sciences, Bratislava, Slovakia; ${ }^{2}$ Laboratory of Molecular Oncology, Cancer Research Institute, Slovak Academy of Sciences, Bratislava, Slovakia

*Correspondence: vladimir.zajac@savba.sk

Received November 6, 2013 / Accepted December 13, 2013

\begin{abstract}
Colorectal cancer mortality is one of the most common cause of cancer-related mortality. A multiple risk factors are associated with colorectal cancer, including hereditary, enviromental and inflammatory syndromes affecting the gastrointestinal tract. Familial adenomatous polyposis (FAP) is characterized by the emergence of hundreds to thousands of colorectal adenomatous polyps and FAP syndrome is caused by mutations within the adenomatous polyposis coli (APC) tumor suppressor gene. We analyzed 21 rectal bacterial subclones isolated from FAP patient 41-1 with confirmed 5bp ACAAA deletion within codons 1060-1063 for the presence of APC-like sequences in longest exon 15. The studied section was defined by primers 15Efor-15Erev, what correlates with mutation cluster region (MCR) in which the $75 \%$ of all APC germline mutations were detected. More than $90 \%$ homology was showed by sequencing and subsequent software comparison. The expression of APC-like sequences was demostrated by Western blot analysis using monoclonal and polyclonal antibodies against APC protein. To study missing link between the DNA analysis (PCR, DNA sequencing) and protein expresion experiments (Western blotting) we analyzed bacterial transcripts containing the 15Efor-15Erev sequence of $A P C$ gene by reverse transcription-PCR, what indicated that an $A P C$ gene derived fragment may be produced. We observed 97-100 \% homology after computer comparison of cDNA PCR products. Our results suggest that presence of APC-like sequences in intestinal/rectal bacteria is enrichment of bacterial genetic information in which horizontal gene transfer between humans and microflora play an important role.
\end{abstract}

Key words: colorectal cancer, familial adenomatous polyposis, bacterial flora, APC-like sequences, APC-like protein

Colorectal cancer is the second most frequent cause of cancer death in developing countries and the incidence of CRC is rapidly increasing especially in populations that are adopting Western-style diets $[1,2,3]$. The development of cancer is a complex multistage process of successive changes and there is increasing evidence that bacteria can contribute to specific stages in the cancerogenous process $[4,5,6,7]$. The idea that certain bacteria are capable of causing cancer is further supported by studies of animal-specific pathogens that promote tumor formation in rodents. An example is Helicobacter hepaticus - a cause of chronic active hepatitis that progressed to hepatocellular carcinoma in A/JCr mice [8]. H. hepaticus also promotes formation of colon cancer in genetically altered mice, either on its own $[8,9,10]$ or in conjuction with Helicobacter bilis [11]. Salmonella typhimurium can also be a potential etiological agent of cancer [12]. The obligate intracellular bacterial pathogen Lawsonia intracellularis in many animal species [13] have been associated with intestinal epithelial hyperproliferation, a known biomarker for cancer risk [14].

Citrobacter rodentium causes a self-limiting condition of epithelial hyperproliferation without an appreciable inflammatory infiltrate and is sufficient to cause colon tumor development. C. rodentium-induced transmissible murine colonic hyperplasia model provides an excellent template to study how alterations in intestinal stem cells promote trans-differentiation and colon carcinogenesis following bacterial infection $[15,16]$. Although $C$. rodentium is not a human pathogen, the bacterial genes ( $35 \mathrm{kbp}$ pathogenicity island) required for infection and presumably for the induction of epithelial cell hyperplasia are genetically similar to enteropathogenic and enterohemorrhagic Escherichia coli [14]. Furthermore, C. rodentium infection causes increased cellular cytosolic and nuclear $ß$-catenin levels in colon epithelial cells in vivo and mutations in the APC pathway lead to promotion of colon cancer, implying that the signals 
delivered to the epithelium from infecting bacteria might exacerbate defects in developmental or oncogenic pathways in the tissue $[14,17]$.

Giannakis et al. [18] examined the expression profile from epithelial progenitors in the stomach and small intestine and reported that $\mathrm{Wnt} / \mathrm{B}$-catenin and TGFß signaling pathways may play a significant role in stem-cell homeostasis in gastric epithelial progenitors. Helicobacter pylori infection was found to be associated with an increase of $B$-catenin transcriptional activity in a CagA-dependent manner in a gastric epithelial cancer cell line [19]. Coexpression of CagA with a loss-offunction allele encoding the $\beta$-catenin destruction complex protein Axin 1 resulted in a further increase in intestinal proliferation. Coexpression of CagA with a null allele of the key $\beta$-catenin transcriptional cofactor TCF4 restored intestinal proliferation to wild-type levels. These results provide in vivo evidence of Wnt pathway activation by CagA downstream of or in parallel to the $\beta$-catenin destruction complex and upstream of TCF4 [20].

APC (Adenomatous Polyposis Coli) gene is a part of the destruction complex that negatively regulates $B$-catenin as the central signaling molecule of the classical Wnt pathway. Mutations within the APC protein result in stabilization of $B$-catenin and consequently lead to enhanced proliferation of the intestinal epithelium [21]. Data from gene expression analyses indicate that both parallel and cooperative mechanisms of Wnt and Ras signaling are responsible for the initiation and progression of intestinal tumorigenesis after APC loss [22]. Mutations in the APC tumor suppressor gene result in the Familial Adenomatous Polyposis (FAP) syndrome. FAP is an autosomal inherited disorder characterized by the emergence of hundreds to thousands of colorectal adenomatous polyps in the gut, with an almost $100 \%$ probability of degeneration into a malignant process by the age of $40[23,24,25]$. A mutational hot spot has been identified within the $5^{\prime}$ region of the last coding exon of the $A P C$ gene, also known as MCR (Mutation Cluster Region), between codons 1286-1513. Patients with a mutation in MCR domain develop adenomas at very young age and the risk of finding more than 1000 colorectal adenomas is significantly higher. In MCR are two specific critical spots induced by a polymerase slippage error. First hotspot is $5 \mathrm{bp}$ deletion AAAAG or AAAGA between codons 1307-1311 and the second mutations hotspot is 5bp deletion ACAAA within codons 1060-1063[26]. Most disease-causing mutations lead to premature stop codons or frame shifts, resulting in synthesis of truncated APC proteins $[27,28,29]$. The induction mechanism of the other APC gene mutations remains still unanswered. This work was undertaken to study the scarcely recognized interactions between human hosts and bacterial organisms, provoked by recently published reports suggesting that bacteria are often not sufficient to induce cancer on their own, that the process is accompanied by chronic inflammation, and that tumor formation might require independent mutations in oncogenic signaling pathways.

\section{Patients and methods}

Patient's samples. In our previous work we have detected APC-like sequences mainly in MCR region of the APC exon 15 in rectal swabs bacteria from 15 various FAP patients [30]. According to these results we have analyzed 21 bacterial subclones isolated from rectal swabs of FAP patient 41-1 with determined 5-bp deletion ACAAA within codons 1060-1063, diagnosed with aggresive form of FAP characterized by thousands of polyps in age of 19. Based on molecular diagnostic patients having 41-1 underwent successful colectomy.

DNA extraction. Bacterial subclones were cultivated in $\mathrm{LB}$ medium overnight at $37^{\circ} \mathrm{C}$. Individual bacterial clones were prepared after dilution $10^{-9}-10^{-11}$ on LB agar plates and incubated overnight at $37^{\circ} \mathrm{C}$. Bacterial chromosomal DNA was extracted from amplified bacteria by use of the QIAamp DNA Kit (Qiagen). Plasmid DNA was isolated with protocol QIAprep Spin Miniprep Kit (Qiagen).

PCR amplification. Polymerase chain reaction was carried out using primers 15Efor-15Erev located in exon 15, which determined 332 bp PCR products as described by Groden et al. [31]. PCRs were performed from 150-200 ng of genomic/plasmid DNA, $80 \mathrm{mM}$ dNTP, $1 \mathrm{mM}$ 10x PCR buffer (Qiagen), $0.5 \mathrm{U}$ of Taq polymerase (Qiagen), $10 \mathrm{pmol}$ of each primer, to total volume of PCR mixture of $25 \mu$. DNA samples were amplified under standard conditions: 5 min at $94^{\circ} \mathrm{C}$, once; $1 \mathrm{~min}$ at $94^{\circ} \mathrm{C} ; 1 \mathrm{~min}$ at annealing temperature from $58^{\circ}$ to $63^{\circ} \mathrm{C} ; 1 \mathrm{~min}$ at $72^{\circ} \mathrm{C}, 30$ times; and 7 min at $72^{\circ} \mathrm{C}$, once. To avoid false positive results, we used genomic DNA isolated from commercial strain DH5 $\alpha$ and genomic DNA isolated from bacteria of healthy persons. As a positive control, genomic DNA isolated from blood of healthy persons was used.

DNA sequencing. Amplicons were purified by Auto-Seq G-50 columns (Amersham Biosciences) and bidirectionally sequenced using fluorescent dyes of ABI Prism Big Dye Terminator sequencing kit (Applied Biosystems). Sequencing extensive products were analyzed on a PE Applied Biosystems ABI-PRISM 310 sequencer.

Bioinformatic analysis. The APC gene sequences were analyzed for DNA homology by Vector NTI Advance 11.5, Vector NTI Suite 8 (Invitrogen) software. The sequence data were compared against all known microbial genes using the NIH National Center for Biotechnology Information GenBank Blast Program [28].

Analysis of $A P C$ gene expression. Bacterial subclones isolated from the FAP patient 41-1 were used for preparation of protein extracts from $15 \mathrm{ml}$ overnight cultures in LB medium incubated at $37^{\circ} \mathrm{C}$. As a negative bacterial control, $\mathrm{DH} 5 a$ bacteria protein extracts were used. As a positive control, protein extract from $\mathrm{CaCo} 2$ human cell line was used. Protein extracts were prepared by centrifugation of overnight cultures at $3000 \mathrm{rpm}$ for $15 \mathrm{~min}$. Pellets were sonicated and $10 \mu \mathrm{l}$ of $100 \mathrm{mM}$ PMSF was added and cen- 


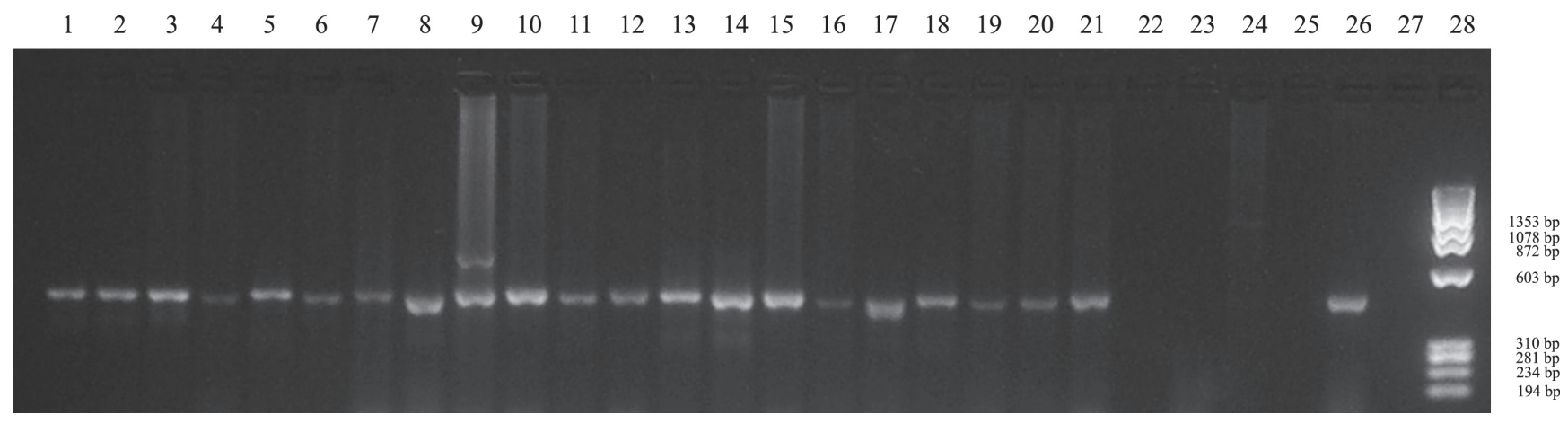

Figure 1. PCR analysis of bacterial DNA isolated from bacterial subclones of the FAP patient determined by primers 15Efor-15Erev. Lines 1: 41-1-2, 41-1-3, 41-1-4, 41-1-5, 41-1-6, 41-1-8, 41-1-9, 41-1-10, 41-1-12, 41-1-13, 41-1-15, 41-1-16, 41-1-17, 41-1-19, 41-1-20, 41-1-24, 41-1-26, 41-1-28, 41-1-29, 41-1-30, 41-1-31, line 22: empty line, line 23: K17-2-5 (bacterial DNA of healthy person), line 24: 41-1-1, line 25: laboratory bacterial strain DH5a, line 26: 156-1 (positive control for $A P C$ gene amplification), line 27: empty line, line 28: phiX174 DNA/BsuRI (HaeIII) Marker .

trifuged at $13000 \mathrm{rpm}$ for $15 \mathrm{~min}$. The prepared cell extracts were subjected to electrophoresis in 10\% SDS-PAGE at 45 $\mathrm{mA}$. The extracted proteins were overnight transferred from acrylamide gel to nitrocellulose membrane (NC Hybon membrane). The membrane was incubated in TBS-T buffer and blocked using $5 \%$ milk for 1 hour at room temperature. The blocking buffer was removed and the membrane was washed with TBS-T buffer. Appropriately diluted mouse monoclonal APC antibody (ALi 12-28, Abcam) and rabbit polyclonal antibody to APC (ab15270) (ALi 12-28, Abcam) in TBS-T buffer with $5 \%$ milk was added to the membrane and incubated overnight at $4^{\circ} \mathrm{C}$ on a shaker with a rocking motion. The membrane was washed with TBS-T buffer and incubated for 1 hour at room temperature in appropriately diluted goat anti-mouse antibody (sc-2005) (Santa Cruz Biotech) or goat anti-rabbit IgG-HRP: sc-2030 (Santa Cruz Biotech) in buffer containing $5 \%$ milk. Consequently, the membrane was washed with TBS-T buffer and visualization was performed by ECL solutions.

Total RNA preparation from up to $10^{9}$ bacterial cells. To homogenize samples, we resuspended the bacterial cell pellet in $100 \mu \mathrm{l}$ TE buffer ( $10 \mathrm{mM}$ Tris-HCl, $1 \mathrm{mM}$ EDTA; $\mathrm{pH}$ 8) containing $1 \mathrm{mg} / \mathrm{ml}$ lysozyme by vigorous vortexing, followed by incubation at $37^{\circ} \mathrm{C}$ for $10 \mathrm{~min}$. Total RNA was prepared according to protocol NucleoSpin RNA II (Mancherey \& Nagel).

Reverse transciption reaction. Reverse transcription reaction was carried out with oligo-dT primers and was performed using Omniscript Reverse Transcription Kit (Qiagen).

\section{Results}

We analyzed 21 bacterial subclones from rectal swabs of the FAP patients having 41-1. About $90 \%$ of the bacteria tested were identified as Escherichia coli. Bacterial subclones were amplified in $\mathrm{LB}$ medium overnight at $37^{\circ} \mathrm{C}$ and each subclone was analyzed for the presence of APC-like sequences using
PCR. The section from exon 15 of the APC gene defined by primers 15Efor-15Erev was analyzed. Human DNA blood sample from a healthy person 156-1 was used as positive control for appropriate PCR amplification. Chromosomal DNA of the laboratory strain DH5 $\alpha$ and rectal bacteria isolated from a healthy person (K17-2-5) were used as negative controls in all reactions.

PCR products of the section 15Efor-15Erev were identified by all samples except for bacterial subclone 41-1-1 of the FAP patient studied (Figure 1, line 24).

PCR products from rectal bacteria, or from their subclones, as well as the patient's DNA sample and healthy control DNA blood sample (156-1) were sequenced in section defined by primers 15Efor-15Erev and subsequently compared using the computer program Vector NTI Suite 8 (Invitrogen). The sequence of human APC gene (NM_001127511) was included in bioinformatic homology comparing. We observed more than $90 \%$ of the rate of homology in this section (Figure 2).

When APC-like sequences determined by primers 15Efor-15Erev were compared against all known microbial genes using GenBank Blast Program, no homology was recorded.

To determine the possible expression of APC-like sequences, we used Western blot analysis with combination of monoclonal mouse APC antibody and polyclonal rabbit antibody to APC (ab15270) protein. As negative control, bacterial extract of DH5a laboratory bacterial strain was used. $\mathrm{CaCo} 2$ cell lysate served for positive protein expression (Figure 3).

Reverse transcription of selected bacterial RNA yielded cDNA (Figure 4), which was subsequently analyzed for the presence of APC-like sequences defined by primers 15Efor15Erev (Figure 5). Positive PCR products were sequenced and subsequently compared with sequence of human $A P C$ gene (NM_001127511), using computer program Vector NTI Advance 11.5 (Invitrogen) (Figure 6). 

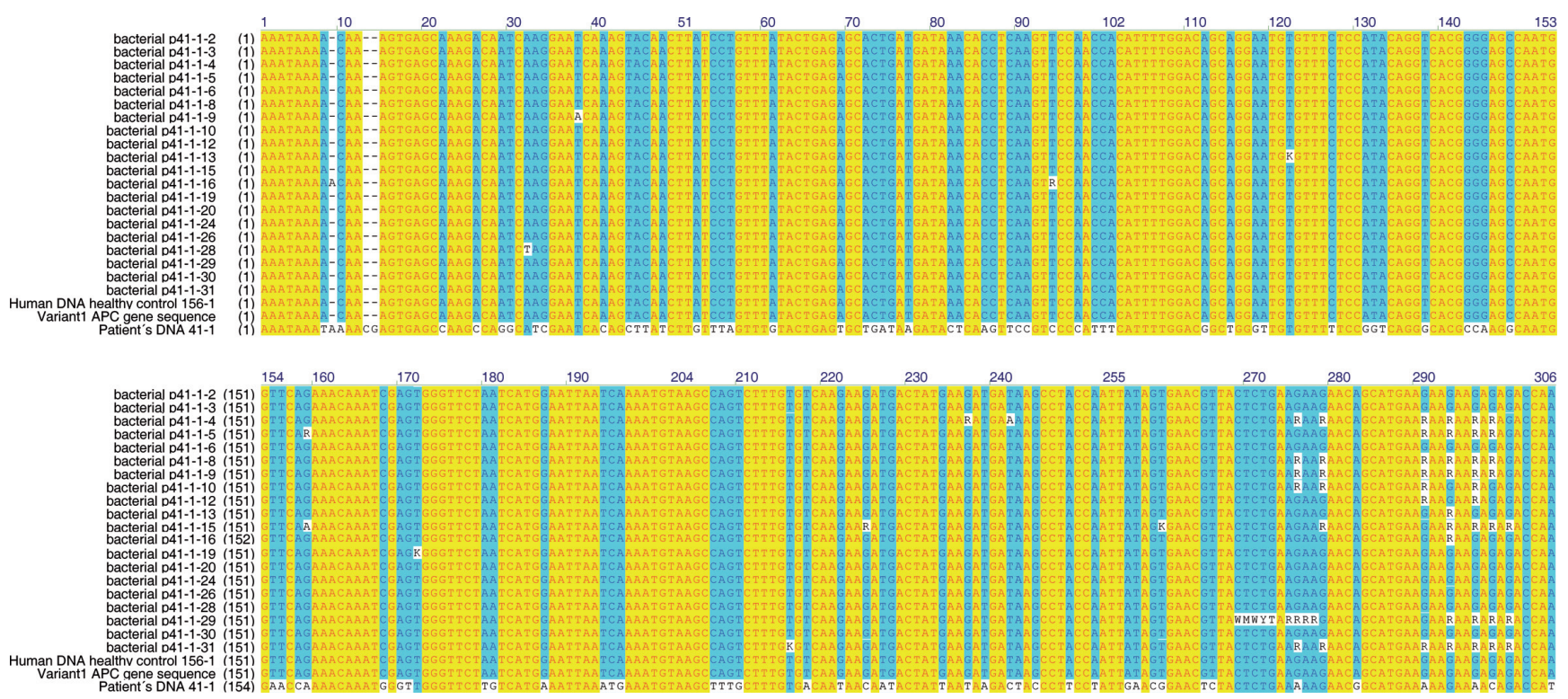

Figure 2. Comparison of sequences 15Efor-15Erev areas from individual bacterial clones isolated from rectal swabs of the FAP patients having 41-1 and controls.

\section{Discussion}

It is well established that the human body is outnumbered by its own microbiome and it is very interesting to study the role of microorganisms in beneficial and detrimental effects on host physiology, contributing to health or disease susceptibility. In this context, there are several reports pointing to the fact that gut microbial communities may influence the development of colorectal carcinoma.

According to the results of Holec et al. [30], we analyzed 21 rectal bacterial subclones isolated from the FAP patients having 41-1 for the presence of APC-like sequences from exon 15 of the APC gene. The section studied of about 332

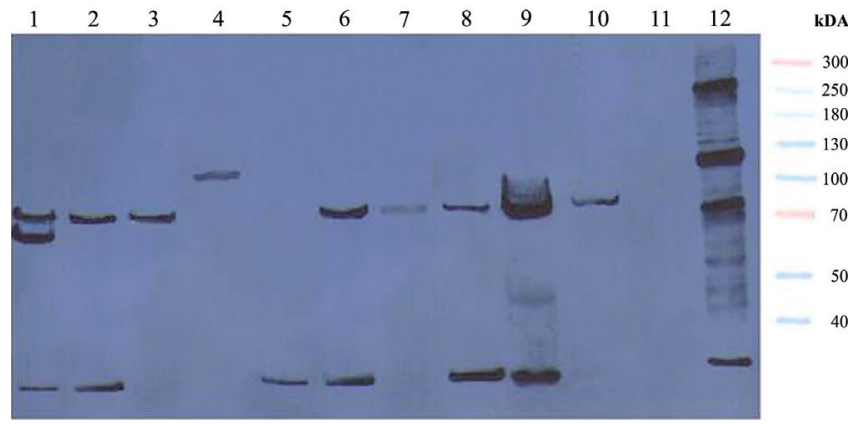

Figure 3. Western blot analysis of APC-like protein expression in 41-1 bacterial subclones from rectal swabs. Line 1-10: 41-1-19, 41-1-3, 41-1-6, 41-1-15, 41-1-16, 41-1-17, 41-1-28, 41-1-29, 41-1-30, 41-1-31, line 11: bacterial extract of laboratory bacterial strain DH5a, line 12: CaCo2 cell lysate. Protein ladder: Spectra ${ }^{\mathrm{TM}}$ Multicolor High Range Protein Ladder. bp was defined by primers 15Efor-15Erev, correlating with the MCR area. More than $90 \%$ homology was achieved by sequencing and subsequent software comparison. The expression of APC-like sequences was demostrated by Western blot analysis using monoclonal and polyclonal antibodies against APC protein. To study the missing link between the DNA analysis (PCR, DNA sequencing) and protein expression experiments (Western blotting), we analyzed bacterial transcripts containing the 15Efor-15Erev sequence of the $A P C$ gene by reverse transcription-PCR. The result indicated that an APC gene derived fragment may be produced. We observed 97-100\% homology after computer comparison of cDNA PCR products.

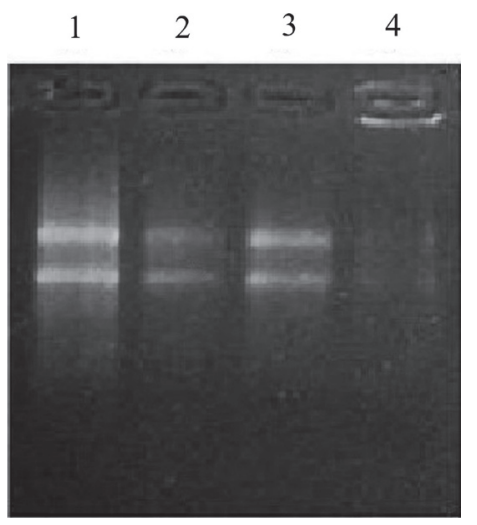

Figure 4. cDNA obtained by reverse transcription of bacterial RNA isolated from bacteria subclones of FAP patients having 41-1. Line 1:41-1-3, line 2: 41-1-6, line 3: 41-1-19, line 4: 41-1-29. 


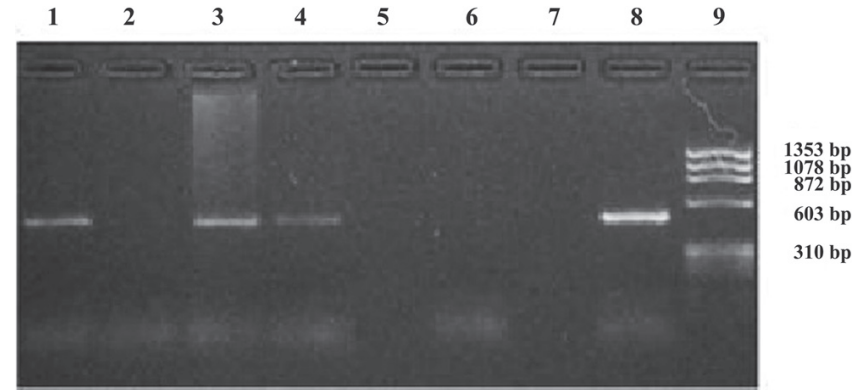

Figure 5. PCR analysis of cDNA transcripted from bacterial RNA determined by primers 15Efor-15Erev. Line 1: cDNA 41-1-3, line 2: cDNA 41-1-6, line 3: cDNA 41-1-19, line 4: cDNA 41-1-29, line 5: empty line, line 6: cDNA of healthy bacterial control K17-2-5, line 7: empty line, line 8: PCR amplification control 156-1, line 9: phiX174 DNA/BsuRI (HaeIII) Marker.

The long list of cancer risk factors has expanded to include infectious agents. The role of viruses (expecially small DNA viruses) in human cancer, including Merkel cell carcinoma, cervical cancer, Burkitt's lymphoma, Hodgkin's lymphoma, nasopharyngeal carcinoma, is well recognized. Evidence has been accumulating in the literature concering the link between bacterial infection and cancer. Data derived from clinical and laboratory trials substantiate the fact that several bacteria have been identified and implicated in the development of colorectal cancer, e.g.: Streptococcus bovis, Helicobacter pylori, Escherichia coli, Klebsiella pneumoniae and Fusobacterium sp. There are some studies reporting that bacteria can cause colorectal cancer through direct mutagenesis, secretion of mutagenic products and/or prolonged infection, as well as through inflammation, leading to increased epithelial cell proliferation, which is associated with the potential to preferentially select cancerogenic clones [7,12,32].

Familial adenomatous polyposis is a disease associated with germ-line mutations at the $A P C$ gene. It was reported that colon cancer cells retain truncated APC fragments which may lead to the stabilization of $\beta$-catenin and to the constitutive activation of Wnt signaling, essential for cell proliferation. Activation of the growth-promoting Wnt pathway compensates the negative effect on cell growth caused by the reduced $A P C$ gene dosage $[20,33]$. APC also mediates several other normal cell functions independently of Wnt/ $\beta$-catenin signaling such as: apical-basal polarity, microtubule networks, cell cycle, DNA replication and repair, apoptosis, and cell migration. Given the vast cellular processes involving APC, the loss of these "normal“ functions due to mutation can contribute to chemotherapeutic resistance. The APC fragment may have a function indispensable for cell proliferation and cell survival. This function would be lost upon a full APC deletion and thus contribute actively to tumorigenesis. Some reports showed that truncated fragments of APC enhanced the migratory capacity of colon cancer [34,35]. Mutations of the FAP syndrome as well as somatic mutations in the $A P C$ gene are clustered in the MCR and are associated with synthesis of the truncated $A P C$ fragment lacking roughly the $\mathrm{C}$-terminal half. Truncation in the MCR removes the tumor suppressor activity of APC [33]. Based on positive PCRs in the samples analyzed in the section defined by primers 15Efor-15Erev, we may assume that the produced APC-like protein may hypothetically contain $\beta$-catenin binding site and bind to $\beta$-catenin, and so it may control the ability to activate transcription.

There are some hypothetical explanations of the presence of APC-like sequences in bacterial subclones isolated from rectal swabs of the FAP patient. A potential scenario of the presence of APC-like sequences in intestinal/rectal bacteria is enrichment of bacterial genetic information in which horizontal gene transfer between humans and microflora play an important role [36]. Because the bacteria are very reluctant to accept any genetic information, it is not excluded that in some bacteria may be present sequences of other eukaryotic genes. This process could occur after an apoptic or necrotic event in which the host DNA is fragmented or disrupted within the dying cells, or alternatively there is active secretion of neutrophil extracellular traps [37]. Examples of bacterial integration of host genetic information are exceedingly rare, despite the countless interactions between commensal or pathogenic bacteria and their cognate host organisms. Incorporation and acquisition of genetic material between nonmating species, or horizontal gene transfer, was frequently described for phylogenetically related organisms, but far less evidence exists for horizontal gene transfer between highly divergent organisms. Anderson et al. described horizontally transferred fragment of the human long interspersed nuclear element L1 to the genome of the
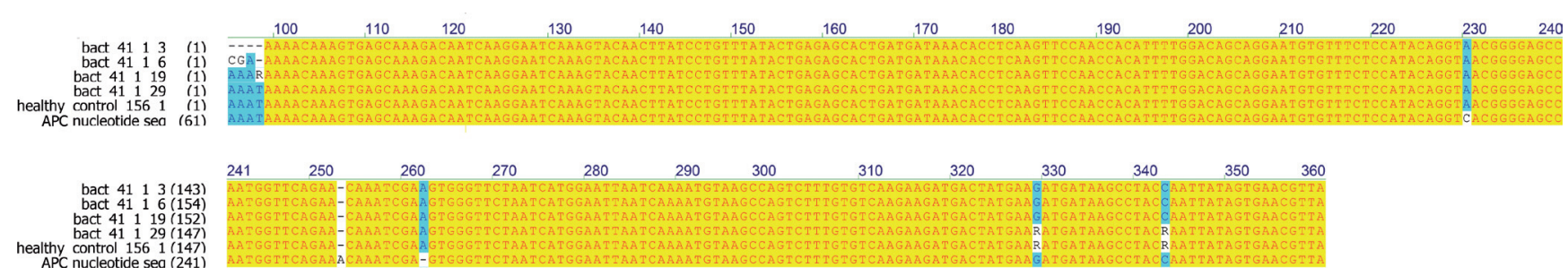

Figure 6. Comparison of sequences 15Efor-15Erev areas from cDNA of transcripted bacterial RNA. Healthy control 156-1 and the sequence of human APC gene (NM_001127511) were used for bioinformatic homology analysis. 
strictly human pathogen Neisseria gonorhoeae. N. gonorhoeae transcripts contained L1 sequence, so L1-derived gene products may be produced $[36,38]$.

Phylogenetic analyses demonstrated that both lateral gene transfer from eukaryotic hosts and bacterial genes that became eukaryotic-like by gradual adaptation to the intracellular milieu or gene fragment acquisition, contributed to the existing repertoire of eukaryotic-like proteins [39]. In the sudy Anderson and Seifert was described, that the active secretion of neutrophil extracellular traps provides a means by which host DNA could become accessible to extracellular $\mathrm{N}$. gonorrhoeae. In the same study was reported that the recombined fragment is the result of a simple insertion with no loss or gain of flanking chromosomal information, what may be one of the possible mechanism of horizontal gene transfer. The second possible mechanism of horiontal gene transfer is non-homologous end joining (NHEJ) recombination which could occure between fragmented copy of human gene and the recipient region of the bacterial genome. Although some bacterial species lack NHEJ machinery, alternative pathways of low frequency NHEJ have the potential to mediate horizontal gene transfer of exogenous sequences $[38,40]$.

In general, horizontal gene transfer enables prokaryotes to rearrange their genomes dynamically, facilitating responses to changing environmental conditions and invasions of new ecological niches [41]. Genes of different evolutionary origin have distinct patterns of selection, as reflected by their ratio of a synonymous vs. synonymous mutations. One eukaryotic like protein is common to several strains of Legionella sp., but outside this genus has homologs in Acanthamoeba polyphaga mimivirus, indicating that gene exchange involving eukaryotic viruses and intracellular bacterial pathogens may also contribute to the evolution of virulence in either or both of these groups of organisms [39]. The certain physiological function of APC-like sequences in bacteria is unknown. We may only assume the possible physiological function. APC-like sequences may play a role in molecular evolution and serve as a "pattern“ for creation of tumor suppresor genes in higher organisms, what is supported by detection of the conserved domain defined by primers 15Efor-15Erev in the sequences of bacterial subclones 41-1. Conserved domains are defined as recurring units in molecular evolution, indicating that this part of APC-like sequences may be an integral part of bacterial genetic information and may serve as "pattern“ for creation of tumor suppressor genes in higher organisms. Exon 15 of the APC gene, which contains a section defined by primer EforErev, may be from the evolutionary point of view the oldest part of the APC gene and the other exons may have joined accidentally during evolution. The other explanation of physiological function of APC-like sequences in bacterial organisms is that the APC-like protein might lead to activation of Wnt signaling through stabilization of $\beta$-catenin. This explanation is based on report Schneikert and Behrens where colon cancer cells retain truncated APC fragments [33]. In the sequences of bacterial subclones $41-1$, defined by primers $15 \mathrm{Efor}-15 \mathrm{Erev}$, a conserved domain was found. Conserved domains are defined as recurring units in molecular evolution, indicating that this part of APC-like sequences may be an integral part of bacterial genetic information and may serve as "pattern“ for creation of tumor suppressor genes in higher organisms. Exon 15 of the APC gene, which contains a section defined by primer Efor-Erev, may be from the evolutionary point of view the oldest part of the APC gene and the other exons may have joined accidentally during evolution.

The high degree of identity (97-100 \%) between the APC gene sequence determined by primers $15 \mathrm{Efor}-15 \mathrm{Erev}$ in bacterial subclones may indicate that a gene transfer event can occur between a mammalian host and resident bacterium, which has important implications for the co-evolution of both humans and their associated microorganisms. According results of Spadafora and other research groups, hypothetically could also consider the possibility that bacterial APC-like sequences having certain mutations may be incorporated in vivo into germ cells (e.g., sperm) and the mutation can then be transferred and integrated into oocytes ready for cutting process $[42,43]$. This hypothesis could give an answer to the extremely high number of mutations in the MCR.

The presented study is a pilot project. Our results are considered only as hypotheses for generating more research, which is highly warranted.

Acknowledgements: This work was supported by the grants VEGA 2/0096/11, VEGA 2/0170/13, grant APVV-0404-07 and APVV-06-4611. This publication is also the result of the project implementation: SF ITMS project code: 26240220058 supported by the Research \& Development Operational Programme funded by the ERDF.

\section{References}

[1] BOYLE P, LANGMAN JS ABC of colorectal cancer: Epidemiology. BMJ 2000; 321: 805-808. http://dx.doi. org/10.1136/bmj.321.7264.805

[2] BOYLE P, FERLAY J Cancer incidence and mortality in Europe. Ann Oncol 2005; 16: 481-488. http://dx.doi.org/ $\underline{10.1093 / \text { annonc/mdi098 }}$

[3] KIM E, COELHO D, BLACHIER F Review of the association between meat consumption and risk of colorectal cancer. Nutr Res 2013; 33: 983-994. http://dx.doi.org/10.1016/ j.nutres.2013.07.018

[4] ZUR HAUSEN H Streptococcus bovis: causal or incidental involvement in cancer of colon? Int J Cancer 2006; 119: 2127-2135.

[5] DALTON-GRIFFIN L, KELLAM P Infectious causes of cancer and their detection. J Biol 2009; 8: 67. http://dx.doi. org/10.1186/jbiol168

[6] ROWLAND IR The role of the gastrointestinal microbiota in colorectal cancer. Cur Pharm Des 2009; 15: 1524-1527. http://dx.doi.org/10.2174/138161209788168191

[7] YAO ZW, ZHOU YB Progress of research in the relationship between microorganisms and colorectal cancer. Zhonghua Wei Chang Wai Ke Za Zhi 2013; 16: 1127-30. 
[8] YANG J, JI S, ZHANG Y, WANG J Helicobacter hepaticus infection in primary hepatocellular carcinoma tissue. Singapore Med J 2013; 54: 451-457. http://dx.doi. org/10.11622/smedj.2013153

[9] ENGLE SJ, ORMSBY I, PAWLOWSKI S, BOIVIN GP, CROFT $\mathrm{J}$ et al. Elimination of colon cancer in germ-free transforming growth beta 1-deficient mice. Cancer Res 2002; 62: 6362-6366.

[10] MAGGIO-PRICE L, TREUTING P, BIELEFELDT-OHMANN $\mathrm{H}$, SEAMONS A et al. Bacterial infection of Smad3/Rag2 double-null mice with transforming growth factor-beta dysregulation as a model for studying inflammation-associated colon cancer. Am J Pathol 2009; 174(1):317-29. http://dx.doi. org/10.2353/ajpath.2009.080485

[11] MAGGIO-PRICE L, TREUTING P, ZANG W, TSANG M, BIELEFELDT-OHMANN $\mathrm{H}$ et al. Helicobacter infection is required for inflammation and colon cancer in SMAD3deficient mice. Cancer Res 2006; 66: 828-838. http://dx.doi. org/10.1158/0008-5472.CAN-05-2448

[12] KUTIKHIN AG, YUZHALIN AE, BRUSINA EB, BRIKO NI Role of infectious agents in emergenec of malignant tumors. Zh Microbiol Epidemiol Immunobiol 2012; (5): 104-14.

[13] LAX AJ, THOMAS W How bacteria could cause cancer: one step on a time. Trends Microbiol 2002; 10(6): 293-9. http:// dx.doi.org/10.1016/S0966-842X(02)02360-0

[14] NEWMAN JV, KOSAKA T, SHEPPARD BJ, FOX JG, SCHAUER DB Bacterial infection promotes colon tumorigenesis in APCMin/+ mice. J Infect Dis 2001; 184: 227-230. http://dx.doi.org/10.1086/321998

[15] COLLINS JW, AKIN AR, KOSTA A, ZHANG N, TANGNEY $\mathrm{M}$ et al. Pre-treatment with Bifidobacterium breve UCC2003 modulates Citrobacter rodentium-induced colonic inflammation and organ specificity. Microbiology 2012; 158: 2826-34. http://dx.doi.org/10.1099/mic.0.060830-0

[16] CHANDRAKESAN P, ROY B, JAKKULA LU, AHMED I, RAMAMOORTHY P et al. Utility of bacterial infection model to study epithelial-mesenchymal transition, mesenchymal-epithelial transition or tumorigenesis. Oncogene 2013; doi: 10.1038/onc.2013.210. http://dx.doi.org/10.1038/onc.2013.210

[17] SELLIN JH, UMAR S, XIAO J, MORRIS AP Increased betacatenin expression and nuclear translocation accompany cellular hyperproliferation in vivo. Cancer Res 2001; 61: 2899-2906.

[18] GIANNAKIS M, STAPPENBECH TS, MILLS JC, LEIP DG, LOVETT $M$ et al. Molecular properties of adult mouse gastric and intestinal epithelial progenitors in their niches. J Biol Chem 2006; 281: 11292-11300. http://dx.doi.org/10.1074/jbc. $\underline{\mathrm{M} 512118200}$

[19] FRANCO AT, ISRAEL DA, WASHINGTON MK, KRISHNA U, FOX JG et al Activation of beta-catenin by carcinogenic Helicobacter pylori. Proc Natl Acad Sci USA 2005; 102: 10646-10651. http://dx.doi.org/10.1073/pnas.0504927102

[20] NEAL JT, PETERSON TS, KENT ML, GUILLEMIN K H. pylori virulence factor CagA increases intestinal cell proliferation by Wnt pathway activation in a transgenic zebrafish model. Dis Model Mech; 6: 802-10. http://dx.doi.org/10.1242/ dmm.011163
[21] FODDE R, KUIPERS J, ROSENBERG C, SMITS R, KIELMAN M et al. Mutations in the APC tumor suppressor gene cause chromosomal instability. Nat Cell Biol 2001; 3: 433-438. http://dx.doi.org/10.1038/35070129

[22] WANG C, ZHAO R, HUANG P, YANG F, QUAN Z et al. APC loss-induced intestinal tumorigenesis in Drosophila: Roles of Ras in Wnt signaling activation and tumor progression. Dev Biol 2013; 378: 122-40. http://dx.doi.org/10.1016/ j.ydbio.2013.03.020

[23] BISGAARD ML, FENGER K, BULOW S, NIEBUHR E, MOHR J Familial adenomatous polyposis (FAP): frequency, penetrance, and mutation rate. Hum Mutat 1994; 3: 121-125. http://dx.doi.org/10.1002/humu.1380030206

[24] HALF E, BERCOVICH D, ROZEN P Familial adenomatous polyposis. Orphanet J Rare Dis. 2009; 4: 22. http://dx.doi. org/10.1186/1750-1172-4-22

[25] KIRCHHOFF T, KULCSAR L, TOMKA M, STEVURKOVA V, ZAJAC V. Characterization of APC exon 15 germ-line mutation in FAP family with severe phenotype showing extracolonic symptoms. Neoplasma 1999; 46: 290-4.

[26] BARROW P, KHAN M, LALLOO F, EVANS DG, HILL J Systematic review of the impact of registration and screening on colorectal cancer incidence and mortality in familial adenomatous polyposis and Lynch syndrome. Br J Surg 2013; 100: 1719-31. http://dx.doi.org/10.1002/bjs.9316

[27] NAGASE H, NAKAMURA Y Mutations of the APC (Adenomatous Polyposis Coli) gene. Hum Mutat 1993; 2: 425-434. http://dx.doi.org/10.1002/humu.1380020602

[28] MUNIAPPAN BP, THILLY WG The DNA Polymerase $\beta$ Replication Error Spectrum in the Adenomatous Polyposis Coli Gene Contains Human Colon Tumor Mutational Hotspots. Cancer Res 2002; 62: 3271.

[29] DIERGAARDE B, VAN MUIJEN GN, KOK FJ, KAMPMAN E Dietary factors and the occurrence of truncating APC mutations in sporadic colon carcinomas: a Dutch populationbased study. Carcinogenesis 2003; 24: 283-290. http://dx.doi. org/10.1093/carcin/24.2.283

[30] HOLEC V, CIERNIKOVA S, WACHSMANNOVA L, ADAMCIKOVA Z, HAINOVA K et al. Analysis of bacteria from intestinal tract of FAP patients for the presence of APC-like sequences. Med Sci Monit 2012; 18: CR486-492. http://dx.doi. org/10.12659/MSM.883268

[31] GRODEN J, THLIVERIS A, SAMOWITZ W et al. Identification and characterization of the familial adenomatous polyposis coli gene. Cell 1991; 66: 589-600. http://dx.doi. org/10.1016/0092-8674(81)90021-0

[32] ANTONIC V, STOJADINOVIC A, KESTER KE, WEINA PJ, BRUCHER B et al. Significance of infectious agents in colorectal cancer development. J Cancer 2013; 4: 227-240. http://dx.doi.org/10.7150/jca.5835

[33] SCHNEIKERT J, BEHRENS J Truncated APC is required for cell proliferation and DNA replication. Int J Cancer 2006; 119: 74-79. http://dx.doi.org/10.1002/ijc.21826

[34] KAWASAKI Y, SATO R, AKIYAMA T Mutated APC and Asef are involved in the migration of colorectal tumor cells. Nat Cell Biol 2003; 5: 211-215. http://dx.doi.org/10.1038/ ncb937 
[35] LESKO AC, GOSS KH, PROSPERI JR Exploiting APC Function as a Novel Cancer Therapy. Curr Drug Targets 2013; [Epub ahead of print].

[36] ANDERSON MT, SEIFERT HS Opportunity and means: Horizontal gene transfer from the human host to a bacterial pathogen. 2011; mBio2(1): e00005-11.

[37] WALKER PR, SIKORSKA M Endonuclease activities, chromatin structure, and DNA degradation in apoptosis. Biochem Cell Biol 1994; 72: 615-623. http://dx.doi.org/10.1139/094-081

[38] ANDERSON MT, SEIFERT HS Neisseria gonorrhoeae and humans perform an evolutionary LINE dance. Mob Genet Elements 2011; 1: 85-87. http://dx.doi.org/10.4161/ mge.1.1.15868

[39] LURIE-WEINBERGER MN, GOMEZ-VALERO L, MERAULT N, GLOCKNER G, BUCHRIESER C et al. The origins of eukaryotic-like proteins in Legionella pneumophila. Int J Med Microbiol 2010; 300: 470-81. http://dx.doi.org/10.1016/ j.ijmm.2010.04.016
[40] CHAYOT R, MONTAGNE B, MAZEL D, RICCHETTI M An end-joining repair mechanism in Escherichia coli. Proc. Natl. Acad. Sci. U. S. A. 2010; 107: 2141-2146. http://dx.doi. org/10.1073/pnas.0906355107

[41] GULJAMOW A, JENKE-KODAMA H, SAUMWEBER $\mathrm{H}$, QUILLARDET P, FRANGEUL L et al. Horizontal gene transfer of two cytoskeletal elements from a eukaryote to a cyanobacterium. Curr Bio 2007; 17: R757-9. http://dx.doi. org/10.1016/j.cub.2007.06.063

[42] BIRNSTIEL ML, BUSSLINGER M Dangerous liaisons: Spermatozoa as natural vectors for foreign DNA? Cell 1989; 57: 701-702. http://dx.doi.org/10.1016/0092-8674(89)90782$\underline{4}$

[43] LAVITRANO M, CAMAIONI A, FAZIO VM, DOLCI S, FARACE MG, SPADAFORA C Sperm cells as vectors for introducing foreign DNA into eggs: Genetic transformation of mice. Cell 1989; 57: 717-723. http://dx.doi.org/10.1016/0092$\underline{8674(89) 90787-3}$ 